\title{
Self-Reference in the Leads of Institutional Press RELEASES
}

\begin{abstract}
The paper investigates the phenomenon of self-reference as an instance of preformulation in the genre of institutional press release, situating it into a more general framework of representation of social actors in the lexico-grammatical and semantic structure. The study is based on a corpus of governmental press releases from two institutions with a similar socio-political function, and it focuses on the opening sentences of the releases which take the function of leads. While the analysis of the data confirms sharp qualitative differences in the nature of self-referencing, especially with regard to their relative position on the informative - promotional axis whose two ends are prototypically represented by news reporting and advertising, the findings also indicate that the structural and lexical differences hardly affect the deeper cognitive semantic patterns relating to the construal of agency.
\end{abstract}

Key words

Self-reference; social actors; institutional press release; construal of agency

\section{Introduction}

The genre of institutional press release (IPR) can be contextualized as an important part of genre chain on the way from the policy paper to the media reporting. According to Fairclough (2003), genre chains are created by various genres that are linked together on a regular basis, while undergoing systematic transformations on the way from one to another. According to Catenaccio et al. (2011: 1844), such transformations are a key characteristic of the news, as "news is all about retelling, intertextuality, and, by extension, entextualization [...] i.e., the 
extraction (decontextualization) of meaning from one discourse and consequent insertion (recontextualization) of that meaning into another discourse". An example could be official documents, associated press releases and reports in the press. As "[c]hange in genre chain is a significant part of social change" (Fairclough 2003: 216), the genre of IPR with its natural focus on positive self-representation invites a reflection on the construal of agency related to social actors. In effect, the study of IPR in the framework of critical discourse analysis (CDA) sheds light on the mode of governance ${ }^{1}$ as enacted in the social structure.

The phenomenon of self-reference as an instance of pre-formulation in the genre of institutional press release (cf. Jacobs 1999a) is examined by comparing it to other-reference. Two analogous governmental institutions operating in different geographical regions were selected to ground the analysis. It is assumed that the perspective adopted in the study leads to finer differentiation, which can then be connected to an insight into the socio-political function of the genre, as well as into the nature of the relevant generic constants. The analysis focuses on the leads as an ideologically prominent part of both press and newspaper reporting, and, in particular, on how agency is construed by means of linguistic and semantic structure.

The aim of the analysis is thus twofold. On the one hand, it highlights the patterns related to the structural representation of social actors which allow ranking the two types of IPR data on the promotional - journalistic generic axis, thus shedding light on the inner differentiation of the genre of institutional press release. On the other hand, by examining the semantic patterns of attributing linguistic agency to social actors, it contextualizes the data within a more general policy discourse, with the argument that "media offers a glimpse into power hierarchies and access into public space, where some participants are better positioned to voice their opinions" (Põiklik 2012: 28).

\section{The genre of institutional press release}

It is generally understood that press releases are one of the more direct ways to communicate with external audiences, and they help organizations to get the media pass their views on to the public. Bait argues that

"[i]n order to get media coverage, government agencies act as a sort of news outlet and take on a pro-active role, taking the initiative rather than leaving journalists with the advantage of probing with inquiries and interviews." (Bait 2004: 12)

Research demonstrates that such publicity can be successful, and, according to Bell (1991: 58), "[a] well written press release about something with news value has a high chance of being picked up and published largely untouched". In terms of communicative purpose, it is therefore substantiated to claim that besides the 
obvious informative function, the prevailing communicative purpose of press releases is promotional, and thus can be seen as an instance of what Bhatia (1993: 45-75) calls promotional genres. Strict objectivity of providing balanced information assumes secondary importance, and information is selectively used to enhance positive self-appraisal.

Lassen (2004: 264) argues that backgrounding of the maxim of quality (cf. Grice 1975), resting upon providing sufficient evidence, might well be a defining stylistic feature, and points to the vagueness characteristic of press releases.

It can therefore be claimed that alongside the informative function, i.e. to communicate news about an organization relating to a specific event or development to a wide audience, the promotional function comes to the foreground, which is aimed at serving public relations needs of an organization and generating a positive image of it. In other words, information is given in such a way as to promote the issuing subject. In this connection, Hess (1989: 47, as cited by McLaren and Gurau 2005: 12) notes that press releases are "an agency's opportunity to order information in a manner that the agency considers most advantageous to its mission."

McLaren and Gurau (2005) in their study on corporate press releases describe the genre as "hybrid", in the sense that press releases "seek both to inform and to persuade". This is in line with the study of 600 Dutch press releases undertaken by Jacobs (1999b), who points to the dual function of the genre, claiming that press releases occupy the middle ground between advertising and news reporting. He describes press releases as "egocentric", as "organizations invariably issue them when they want to say something about themselves" (Jacobs 1999b: 220). In his study on genre mixing in respect of press releases, Maat (2007: 59-61) claims that the tendency to generate a positive self-image is not confined to corporate genres, and asks whether the promotional purpose of press releases might be in conflict with the more distanced journalistic style.

From the point of view of our analysis, Ungerer's (2004) findings on the hybridization between advertisements and newspaper articles are more 'tailored' to the subject field in focus, as a more refined link to news values is established. The author weighs the genres against two underlying principles, that of credibility (prototypically for news writing) and desire (prototypically for advertisement). According to Ungerer (2004: 320), focusing on the imitation of prototypes of the superimposed genre and considering the conceptual lag involved in adapting these prototypes to genre development gives us "a chance to get hold of textual hybridity between ads and news stories". He concludes that "although the interaction is most spectacular between ads and news stories, it is no less common between ads and other newspaper genres" (Ungerer 2004: 307). It should be noted that such generic hybridity is commonly identified in other media texts as well, where informative function is blended with a more 'desire'-oriented one. Chovanec's (2009: 124) analysis of live text commentary as a subgenre of sports reporting is a case in point: "it is meant not only to provide information about a currently played match, but also to help construct the virtual group of readers and contribute to their virtual social bonding in the online environment". 
Understanding credibility and desire as genre-specific principles roughly equivalent to the informative and promotional functions as outlined above, the following corpus-based qualitative analysis will attempt to give an insight into the inner differentiation of the genre of IPR with regard to the two categories.

\section{Data and methodology}

The corpora consist of 83 press releases issued by the European Commission (EC) and 71 press releases issued by the UK environmental department (DEFRA). The compatibility of the material compared is granted by the fact that the institutions are analogous in function, as well as restricting the topic coverage to the (highly controversial) issue of climate change. The following criteria were applied to compile the corpora: press releases were issued under the 'environment' section; PR must contain at least one of the keywords climate change and carbon while the corpora have been cleaned manually of releases that, although containing one of the keywords, address a topic that is not directly related to climate change, e.g. a release on smoking; in case of EC, it was published between 21 October 2005 that marks the start of the second European climate change programme (a turning point in the EU policy making in the area of climate change) and 28 March 2008 marking the latest developments at the time of corpus compilation. As for the DEFRA counterpart, all the press releases closest to the latter date while not exceeding it were drawn to make up a corpus matching the size of the EC corpus (i.e. 66000 words). ${ }^{2}$

Methodologically, a basic distinction will be made between social actors and linguistic actors. Social actors are equated to the journalistic 'who', covering any participants in the social processes such as institutions (e.g. the European Commission, local authorities), other socially defined groups (e.g. the retired, businesses), politicians (e.g. Environment Commissioner Stavros Dimas, Benn), or any other agents (e.g. people, Britons, China). Linguistic actors, on the other hand, are entities that assume the syntactic-semantic role of ACTOR in the grammatical structure. These may be social actors in the semantic structure, or inanimate entities such as regulations, proposals. The present analysis is restricted to the former.

Along the lines of CDA, it is presumed that social actors can be grammatically foregrounded or backgrounded ${ }^{3}$, and that such stylistic treatment is socially/ideologically significant. In the analysis, three main foregrounding/backgrounding strategies are considered.

\section{Clause/phrase elements}

The categories 'foregrounded' as opposed to 'backgrounded' are a matter of degree rather than an 'either-or' choice. This means that on the syntactic level, discourse referents might occupy the most prominent position of a clause element 
in the syntactic structure of the main clause, or they might be part of a pre-modifying or post-modifying phrase, which is the least prominent linguistic treatment when the discourse referent is made explicit. The cases in-between include clause elements in subordinate or embedded clauses. The term 'embedded' is used to refer to elements in clauses other than the main clause.

As for verbal processes, Halliday notes that

"[i]n formal grammar what is said is treated as 'noun clause object of the verb say', meaning a down-ranked or 'embedded' clause [...] But functionally the verbalized clause is not down-ranked; it functions as the secondary clause in a 'clause complex' being either a) directly quoted or b) indirectly quoted. This means that such sequences consist of two clauses." (Halliday 1985: 129)

Such functional perspective, being closer to the point of view of CDA, will be adopted in our analysis as well, where any social actor referred to within a verbalized clause (formally within a direct object) will be treated as being syntactically foregrounded, occupying the position of a clause element on the level of the main clause:

Gas and electricity companies of the future could be as much about helping customers cut their energy use and $\mathrm{CO}_{2}$ footprint as selling units of energy, Environment and Climate Change Minister Ian Pearson said today.

where gas and electricity companies will be treated as an element of the main clause, similarly to Environment and Climate Change Minister Ian Pearson. This will concern all other quotation structures.

\section{Clause participant role}

Apart from foregrounding/backgrounding on the level of clause/phrase structure, the participant ${ }^{4}$ structure is taken into account (cf. Quirk et al. 1985, Huddlestone and Pullum 2002). Van Leeuwen points out that

"[a]gency [...] as a sociological concept is of major and classic importance in CDA [...] but sociological agency is not always realized by linguistic agency, by the grammatical role 'Agent"'. (Van Leeuwen 1996: 32)

Our focus will be on the role of ACTOR in order to determine the degree to which it is conflated with the discourse referent of social actor ('who'), while bearing in mind that "the function of Actor [...] is defined only by its relation to other representational functions such as Process and Goal" (Halliday 1985: 37). The analysis of the corpora shows that most verbs refer to either abstract material processes (launch, decide, publish, propose, confirm, release, approve, agree) or 
verbal processes (announce, say). This is in line with Jacobs' findings (1999a) that semi-performatives in press releases serve pre-formulation, and as such they are a defining feature of the genre. As in the context of the present analysis the agents of both material and verbal processes can be conceptualized as processes of 'doing' something (cf. Halliday 1985: 103), the term ACTOR will be used in a wider sense to refer to the initiator - the person or entity responsible for any process including verbal or mental processes (cf. Mulderrig 2003: 13). In this context, Chilton (2004: 53-54) refers to 'prototypical agent' and 'prototypical patient'. The simplification serves well the objective of the study, which deals with agency as such. The person or entity to which something is done, on the other hand, will be referred to as AFFECTED or RECIPIENT (cf. Quirk et al. 1985), depending on whether it concerns a direct or indirect object in the syntactic clause structure. While it is appreciated that the above classification is a simplification, it is assumed that the level of generality of the roles involved matches the needs of the analyzed phenomenon.

\section{Passivization}

The third means of foregrounding and backgrounding on the level of syntax is through passivization. In the analyzed sample, passive agent is frequently made explicit. According to Fowler,

"[t]he main effect of the [passive transformation] [...] compared with the active equivalent, is to switch the positions of the left-hand and right-hand noun phrases, so that the patient occupies the syntactic subject (left-hand) position, which is usually associated with an agent." (Fowler 1991: 77)

Passivization can thus become a tool for changing the order of the elements, especially if the press release wants to lead on 'what' instead of 'who' to order the elements according to their newsworthiness:

The crucial role of biodiversity in tackling climate change was today highlighted by Barry Gardiner, Biodiversity Minister [...]

Similar effect can be achieved by a comment clause whereby direct speech is imitated:

Climate Change Agreements are continuing to cut carbon dioxide emissions in a wide range of energy/intensive sectors, Environment Minister Phil Woolas told Parliament today.

Instead of 'what', 'who' with 'other-reference' can be positioned as the first element: 
Gas and electricity companies of the future could be as much about helping customers cut their energy use and $\mathrm{CO}_{2}$ footprint as selling units of energy, Environment and Climate Change Minister Ian Pearson said today.

In the context of the present study, both of these linguistic means, although being formally different, have the same function, i. e. to shift self-reference further within the clause, thus foregrounding another discourse referent.

While the main focus of the analysis is on the syntactic-semantic representation, the lexical structure will be considered briefly as well, and the type of designation will be accounted for.

\section{Analysis}

By examining the initial paragraphs of the DEFRA and EC press releases formally marked by a different font, we observe that the category of lead as commonly understood and as outlined by Bell (1991) does not really apply to the EC data. This is already shown by the number of words contained in what we formally perceive as leads, where EC ones contain the average of 112 words, while those of DEFRA average 31 words. EC leads thus significantly divert from the normal length of a newspaper article lead which is usually below 30 words (cf. Bell 1991: 183). The stark contrast in length might, however, provoke the question of what criteria are applied when delineating the borders of the category of lead, and even the question of whether such criteria might not rank as too formal, especially in the light of establishing material for a comparative analysis. Recourse to function thus needs to be taken.

According to Bell, lead serves two basic functions - offering a summary of the story and serving as a springboard for telling the story:

"the lead's function is not solely as a stand-alone abstract [...] the journalistic lead has a dual function. It must begin to tell the story as well as summarizing it [...] It must provide a springboard for telling the whole story, not just a summary." (Bell 1991: 183)

By examining the IPRs of the EC sample, we note a consistent pattern whereby the story is not set off, but effectively told in the opening paragraph marked by bold, only being re-told in greater detail invariably following direct quotations. To illustrate the situation, a representative IPR is analyzed and compared to its DEFRA counterpart. The example was selected based on the semantic correlation with the DEFRA press release, where the same political event is treated - Boosting growth and jobs by meeting our climate change commitments (EC, 23 January 2008) and UK welcomes EU climate change proposals (DEFRA, 23 January 2008).

In the EC press release, the lead is clearly separated from the rest of the text, comprising a distinct paragraph written in bold. Its distinct position is underlined 
by the fact that it is followed by direct quotations, which, in a sense, are a structural rupture to the story; compare:

\section{EC lead:}

The European Commission has today agreed on a far-reaching package of proposals that will deliver the European Council's commitments to fight climate change and promote renewable energy. The proposals demonstrate that the targets agreed last year are technologically and economically possible and provide a unique business opportunity for thousands of European companies. These measures will dramatically increase the use of renewable energy in each country and set legally enforceable targets for governments to achieve them. All major $\mathrm{CO} 2$ emitters will be given an incentive to develop clean production technologies through a thorough reform of the Emissions Trading System (ETS) that will impose an EU-wide cap on emissions. The package seeks to deliver the European Union to reduce greenhouse gases by at least $20 \%$ and increases to $20 \%$ the share of renewable energies in the energy consumption by 2020, as agreed by EU leaders in March 2007. The emissions reduction will be increased to $30 \%$ by 2020 when a new global climate change agreement is reached.

Continuation in the first paragraph:

Commission President, José Manuel Barroso said, "Responding to the challenge of climate change is the ultimate political test for our generation. Our mission, indeed our duty, is to provide the right policy framework for transformation to an environment friendly European economy and to continue to lead the international action to protect our planet. Our package not only responds to this challenge, but holds the right answer to the challenge of energy security and is an opportunity that should create thousands of new businesses and millions of jobs in Europe. We must grasp that opportunity".

We can observe that the six sentences reserved for the EC lead actually constitute a self-contained summary of the story which is then juxtaposed by direct quotations, thus resigning to the function of beginning the story as well. Its semantic structure roughly correlates with the first three paragraphs of the DEFRA press release, where the lead is not marked by distinct font.

The first paragraph of the DEFRA press release, on the other hand, complies with the criteria traditionally applied to leads by journalists, where lead serves as 'a directional summary, a lens through which the point of the story is focused and its news value magnified' (Bell 1991: 183). In the DEFRA lead, the 'summary' packs the 'who', 'when' and 'what' of the story into one sentence, where 'what' shoots off its natural continuation. Compare: 
DEFRA lead:

The UK today welcomed the European Commission's ambitious proposals for tackling climate change and delivering a low carbon economy in Europe.

Continuation in the first paragraph:

The package contains proposals to implement the decisions agreed by EU Heads of State and Government at the 2007 Spring European Council, including a 20 per cent reduction in EU greenhouse gas emissions by 2020 , increasing to 30 per cent when there is an international climate agreement; 20 per cent of total EU energy consumption to come from renewables by 2020; and measures to support the development of carbon capture and storage (CCS) including up to twelve CCS demonstration projects.

Here the head noun of the nominal phrase proposals realizing the 'what' of the story in the lead is replaced by its context-bound hyperonym package and lexical cohesion is asserted by the use of definite article signalling anaphoric reference. Unlike the EC lead followed by quotations, the DEFRA lead melts into the following text without any disruption. In that, it is similar to the first sentence of the EC lead:

EC lead - the first sentence:

The European Commission has today agreed on a far-reaching package of proposals that will deliver the European Council's commitments to fight climate change and promote renewable energy.

Continuation in the following sentence:

The proposals demonstrate that the targets agreed last year are technologically and economically possible and provide a unique business opportunity for thousands of European companies.

Like the DEFRA lead, the EC first sentence comprises a summary of 'who', 'when' and 'what', and its relationship to the following sentence is similar to that of the DEFRA lead to the following paragraph, i.e. it summarizes the story and begins it at the same time, whereby Bell's defining criteria for the lead are evoked. From this perspective, it could be claimed that the first sentence of the EC lead effectively serves the dual function of the lead. Such functional perspective will also guide the analysis, in which the first sentences of both EC and DEFRA IPRs will be examined and refered to as leads based on the fact that they function as such. 


\section{The leading element}

The EC corpus indicates that there is a tendency for press releases to lead on the category of 'who', which is occupied by a linguistic representation of selfreference. In this way, the social actor is assigned the most prominent, or newsworthy role if judged by the principles of news reporting. In most cases it is the proper name of the issuing institution (European Commission) $-62.7 \%$, or its political representative (Stavros Dimas) - 13.6\%. There are only two instances

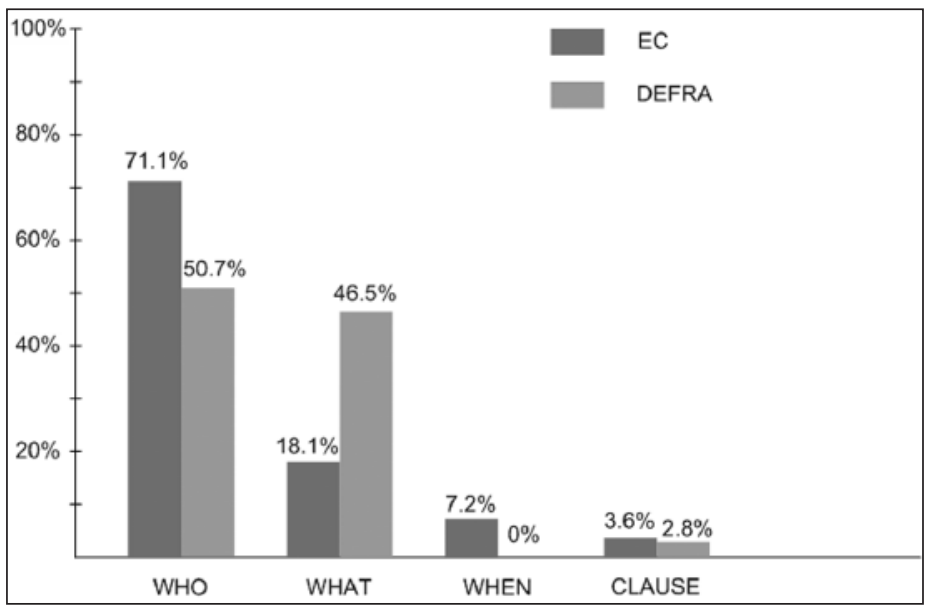

Figure 1. Distribution of 'who', 'when', 'what' and a clause in the leading element in the EC and DEFRA corpora.

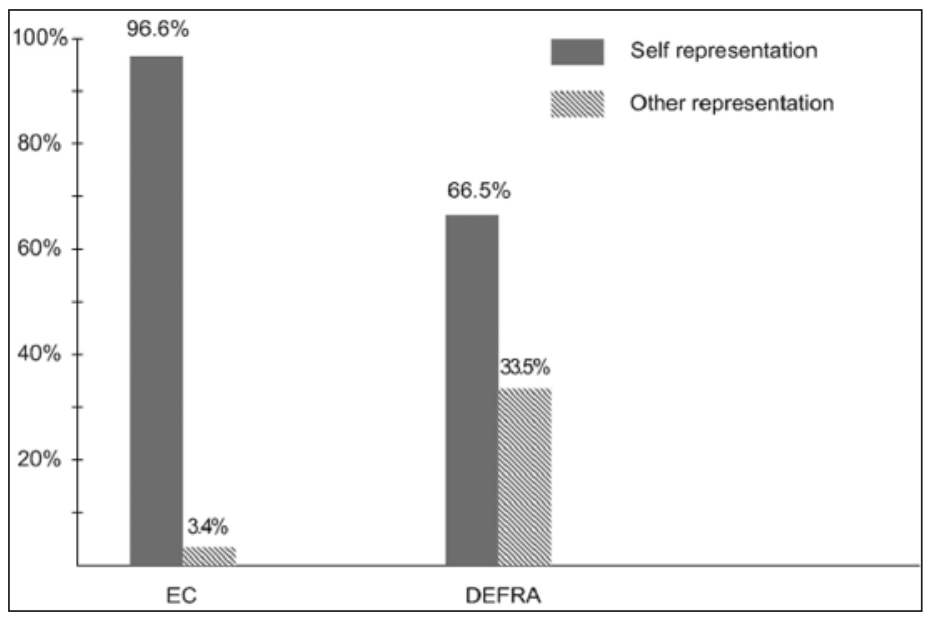

Figure 2. The proportion of self and other representation when leading on a social actor ('who'). 
of other-reference in the leading position in the corpus, out of which one (you) is an embedded form. Together with the form two thirds of Europeans, they comprise $3.4 \%$ of all the references to social actors in the leading position, while the remaining $96.6 \%$ is reserved to self-reference. The strength of the tendency to self-reference in the EC leads is also evident from the comparison with the DEFRA corpus.

As demonstrated in Figure 1 and Figure 2 above, although the greatest percentage of DEFRA press releases also leads on 'who', the percentage is much smaller in proportion to other journalistic ' $\mathrm{W}$ '-s than that applying to the Commission leads. This might be explained by the fact that DEFRA releases are driven more by journalistic principles, notably the principle of newsworthiness, where 'what' may often be more newsworthy than 'who'. Moreover, as can be seen from the figure, the proportion of self-reference when leading on 'who' is smaller than in the Commission corpus.

Greater variety of social actors in the leading position in DEFRA leads as opposed to EC leads can also be noted, with 17 and 6 different social actors respectively. Alongside that fact, there is a more even distribution on the part of DEFRA in terms of their frequency, with the most common label (Defra) amounting to only $13.9 \%$ of the total pie, compared to, e.g., people in $5.6 \%$ of the cases. All of this points to stronger adherance to the journalistic principles on the part of the British ministry, as opposed to favouring promotional generic principles on the part of the European Commission, achieved predominantly by frequent repetition of the 'trademark'.

\section{Foregrounding and backgrounding strategies}

In terms of 'egocentredness', the Commission sample comprises 102 cases of self-reference as compared to 55 cases of reference to other social actors. This is approximately twice the number. Significantly, in the DEFRA corpus, the proportion is much more balanced. Compare:

The two most common realizations of self-reference (apart from $E U$ that mostly appears in an attributive position) are the name of the issuing organization and the environment commissioner. These take up more than half of all instances of self-reference. Generally, the variety of social actors is quite limited, which stands out especially if compared to the DEFRA leads. Here, similarly to the Commission leads, the two most frequently quoted social actors are the issuing institution and the main political representative of the area in concern, although their relative representation in comparison with other social actors is not as prevalent as is the case with the Commission leads.

The issuing organization is most frequently referred to by the acronym Defra (10 instances), rather than by its full name the Department for Environment, Food and Rural Affairs (Defra) (3 instances) or the Department for Environment, Food 


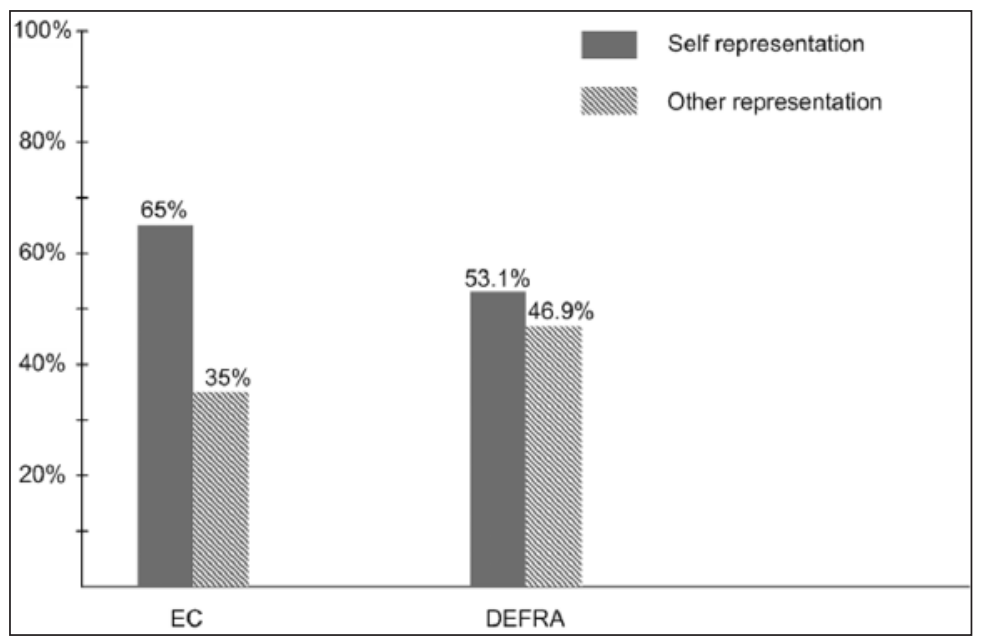

Figure 3. The proportion of self and other representation in the EC and DEFRA corpora.

and Rural Affairs (1 instance). This contrasts the main strategy of self-referencing on the part of the Commission, where the full name the European Commission greatly outnumbers the use of a shortened version. It can be argued that the precision added by the attribute European does not serve information purposes, i.e. avoiding misinterpretation, and it has the function of foregrounding the European perspective which the Commission represents. Such interpretation is supported

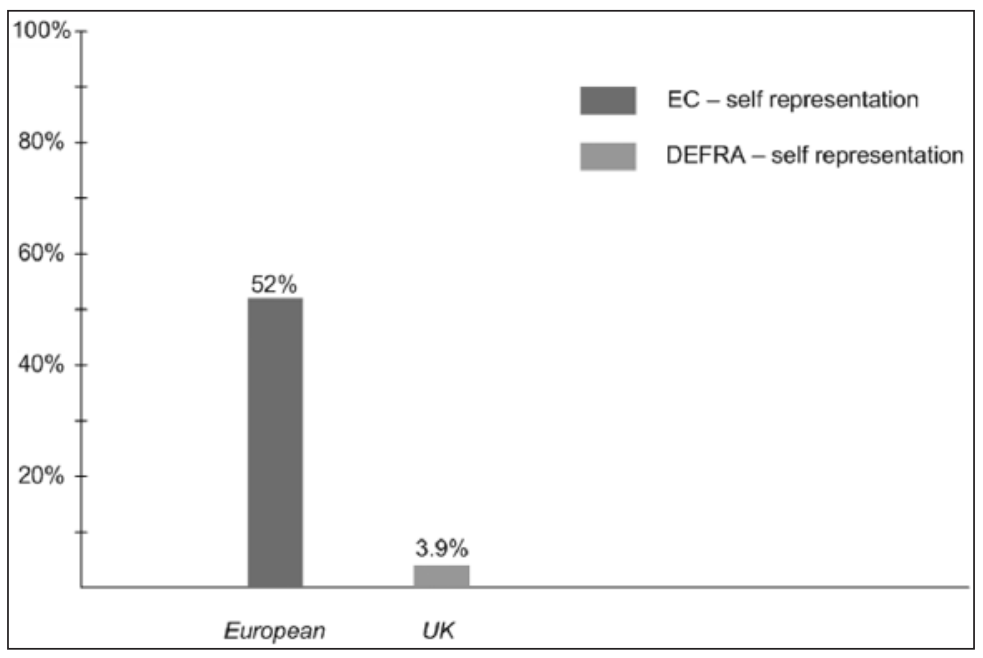

Figure 4. Premodification of social actors by attributive European and $U K$ in EC and DEFRA leads. 
by the use of the adjective in other linguistic representations of social actors, i.e. European Environment Commissioner Stavros Dimas and European Commission President José Manuel Barosso. While European in these coinages has very little informative value, it might even interfere with the conventions of journalism. Bell (1991: 192) comments that '[o]ften a person's full title is too long to fit in the lead and still leave room for the news. Then a generalized label may appear in the lead'. It can therefore be argued that the frequency of European in the designation of social actors in the Commission leads serves the promotional function. This is even more evident in the light of comparison with the analogous phenomenon in the DEFRA leads, i.e. the premodification of linguistic forms by attributive $U K$. The difference is shown in the figure below:

Another significant difference in comparison with self-referencing in the Commission leads is the proportion of personalized self-reference. While the Commission leads refer to politicians as social actors in $17.6 \%$ of all the cases while only 2 different actors are circulated (Commissioner Dimas and Commission President Barosso), the situation is markedly different in DEFRA leads, where personalized self-reference is used on $46.2 \%$ occasions with 10 different social actors involved. It can thus be concluded that DEFRA is more concrete in the designation of social actors than the Commission.

Let us now consider the distribution of syntactic-semantic roles the social actors assume and compare the findings with the grammatical roles assigned to the social actors outside the Commission (other-reference), as well as against the DEFRA analogue:

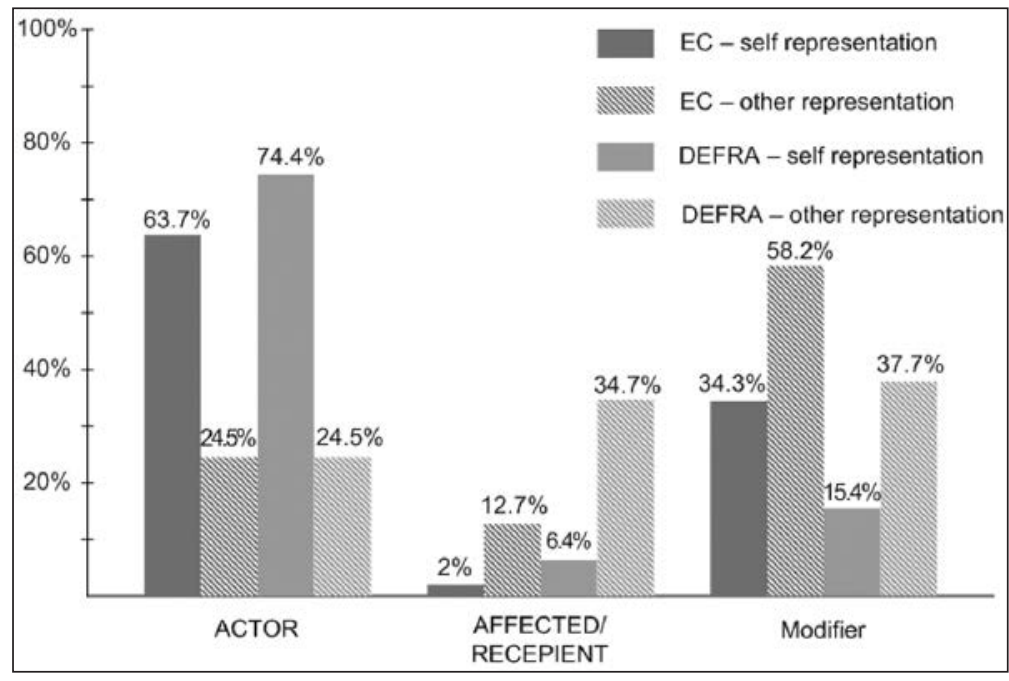

Figure 5. Attribution of agency as opposed to 'beneficiary' and modifying structures in the EC and DEFRA corpora. 
Unlike the data coming out of the earlier comparison of the two corpora, the pattern related to the distribution of participant roles shows remarkable similarity between the two institutions, i.e. the role of ACTOR is prevalently attributed to self-representation. In this connection, van Leeuwen points out that

"[s]ocial actors whose actions are explicitly constructed and purposeful in this way are discoursively empowered as intentional agents - as people who can decide to, and then succeed in, changing the world, whether in minor or major ways, or as people who can set a goal and then determine, autonomously, how to achieve it." (van Leeuwen 2008: 127)

The findings might be compared to Mulderrig's study on the representation of social actors in the educational policy discourse. While teachers would be equivalent to what we hold to be 'other-reference', she finds that

"of the 252 instances of the lemma, only 53 are linguistic agents of processes, while in the remaining cases, it either forms part of a clause fragment like a prepositional phrase (e.g. with the help of teachers), or is the Beneficiary (108 instances)." (Mulderrig 2003: 8)

The above data show that while Beneficiary in the Mulderrig's study (i.e. AFFECTED and RECIPIENT) totals $42.8 \%$, it is a smaller number in the DEFRA corpus $(34.7 \%)$ and much smaller in the EC corpus (12.7\%). This means that other social actors in the EC and DEFRA corpora are more backgrounded as far as syntactic structure is concerned, while they are represented as a clause element (Benefi-

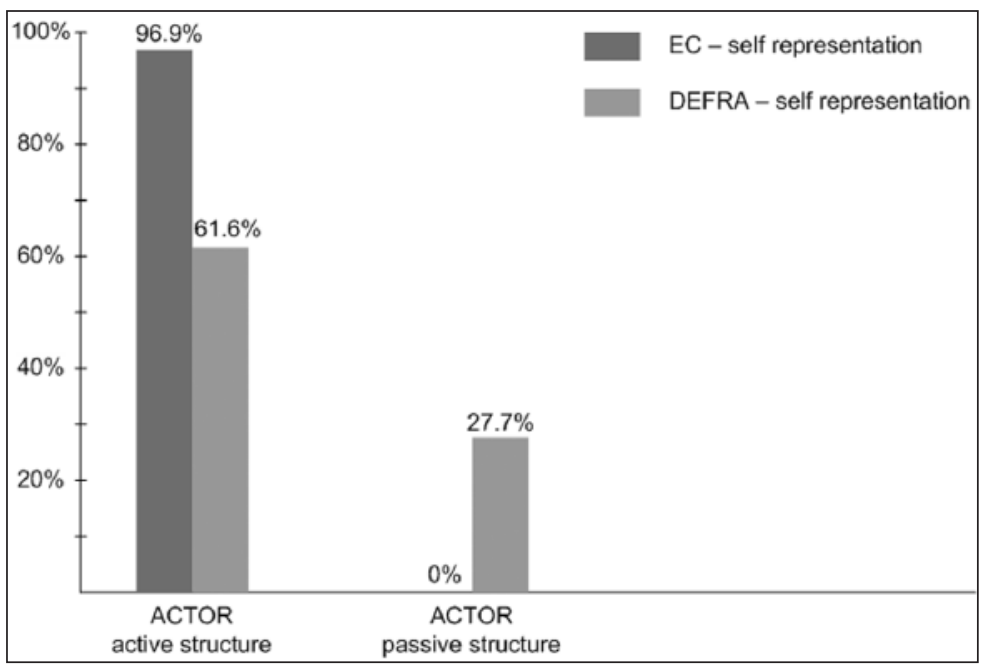

Figure 6. Distribution of active and passive structures related to linguistic agents. 
ciary) more frequently in the educational policy corpus. With respect to linguistic agents (ACTOR in the present paper), the proportion occupied by other social actors is roughly the same in all the corpora, totalling approximately $21 \%$ in Mulderrig's corpus and $24.5 \%$ in both EC and DEFRA corpora. It can thus be concluded that agency attribution represents a constant in respect of the two corpora of the press releases, and approximates the patterns revealed by Mulderrig's study of educational policy discourse.

There is, however, a significant difference in the frequency of ACTOR self-representation via a passive structure. Cf. Figure 6 on the previous page.

While there is no ACTOR passivization in the Commission leads, in DEFRA leads, the ACTOR is passivized in approximately every third case. This should be considered in line with a much stronger tendency observed in the DEFRA corpus to lead on 'what' which pushes 'who' to a further position within the lead, e.g.

A consultation exploring how auctions for the second phase of the EU Emissions Trading Scheme could work was published by the Department for Environment, Food and Rural Affairs (Defra) today.

A consultation on measures to simplify the regulations businesses face in cutting $\mathrm{CO} 2$ emissions, alongside new work from government economists which gives more weight to the cost of carbon in policy decisions, were announced by Environment Minister Phil Woolas today.

It should, however, be added that passivization is not the only syntactic means available for pushing the ACTOR to a further position in the sentence, and this function is frequently served by a loosely attached clause in the DEFRA leads, cf.:

Action by local authorities is crucial to the UK's efforts to cut carbon dioxide emissions, Climate Change Minister Phil Woolas said today, as statistics on local and regional emissions for 2005 were published.

In some cases, the social actor representing the issuing organization might even be pushed to the end of the sentence by 'who' realized by other social actors, cf.:

More investors must send strong signals to the market over the importance of a company's environmental record in making investment decisions, Climate Change Minister Joan Ruddock said today.

While in DEFRA leads the above structures are employed fairly frequently (27 instances accounting for $38 \%$ of all the leads), there is only one such instance in the Commission leads: 
Greenhouse gas emissions from the EU-15 member states rose by $0.3 \%$ between 2003 and 2004, says the European Commission.

The differences between the two corpora in this respect again stress the fact that DEFRA leads are more guided by the principles of news reporting, namely the value of newsworthiness, than is the case with their Commission pendants, where the tendency is towards promotional generic features. Although journalistic principles are more imperative in the DEFRA enactment of the genre of PR, this, in fact, does not affect the attribution of linguistic agency, i.e. the construal of the governing institution as an active, autonomous entity.

\section{Conclusion}

The analysis of the leads of the two institutional press releases has highlighted different polarities on the promotional (appeal to desire) - journalistic (appeal to credibility) generic axis on the part of the European Commission and Defra respectively. This was shown by the proportion of prominent linguistic structures including the initial position in the lead as attributed to social actors, as well as the intensity of 'trademark' repetition. The strategy chosen might have direct influence on the success rate of PR recovery by newspapers, although a further study would be needed to testify this.

The structural and lexical differences, however, hardly affect the deeper cognitive semantic patterns relating to the construal of agency. Such construal is not only remarkably similar between the two corpora, but approximates the results of Mulderrig's study on educational policy. The construal of agency transcends the promotional - journalistic generic variable, and is more intricately tied to the mode of governance, pointing to paternalistic tendencies. The underlying patterns of discursive construal of agency are thus in stark contrast to the formal appeal to partnership proclaimed by both institutions, and seem to be independent of both genre instantiations such as a press release or a more general range of policy discourse texts, as well as of the topic covered (be it climate or educational policy).

\section{Notes}

1 The notion of governance comes from political science. Here, governmentality research is "a critical, diagnostic practice because it seeks to make political reason more intelligible:" (Walters and Haahr 2005: 6), as, according to Foucault, "it's not 'reason in general' that is implemented, but always a very specific type of rationality" (Walters and Haahr 2005: 6). In fact, recent studies in political science pay increasingly more attention to language and discourse, and vice versa, discourse analysis often lends itself to the study of political discourse.

2 The present paper is part of a more extensive study, so the design of the corpora serves to accommodate other related tracks of research. 
Note that in this context, Halliday (1985: 63) speaks of down-ranking.

4 By 'participants' we understand 'entities realized by noun phrases, whether such entities are concrete or abstract' (Quirk et al. 1985: 740).

Huddlestone and Pullum (2002: 228) question the possibility of establishing a small number of general roles "such that all arguments can be assigned to one or other of these roles, with no two arguments in the same clause having the same role".

\section{References}

Bait, Miriam (2004) "Ethical issues in public administration press releases: the WHO Healthy Cities Programme". In: Dossier linguaggi specialistici e interculturalitá. Available at: www.club.it/ culture/culture2004/02culture2004.pdf [Accessed on 11 November 2008]

Bell, Alan (1991) The Language of News Media. Oxford: Blackwell.

Bhatia, Vijay K. (1993) Analyzing Genre. Language Use in Professional Settings. Essex: Longman Group.

Catenaccio, Paola, Colleen Cotter, Mark De Smedt, Giuliana Garzone, Geert Jacobs, Felicitas Macgilchrist, Lutgard Lams, Daniel Perrin, John E. Richardson, Tom Van Hout, Ellen Van Praet (2011) "Towards a linguistics of news production". Journal of Pragmatics 43 (7), 1843-1852.

Chilton, Paul (2004) Analysing Political Discourse. London: Routledge.

Chovanec, Jan (2009) "Simulation of spoken interaction in written online media texts". Brno Studies in English 35 (2), 109-128.

Fairclough, Norman (2003) Analysing Discourse. London and New York: Routledge.

Fowler, Roger (1991) Language in the News. Discourse and Ideology in the Press. New York: Routledge.

Grice, H. Paul (1975) "Logic and conversation”. In: Cole, Peter and Jerry L. Morgan (eds.) Speech Acts. New York: Academic Press, 1-36.

Halliday, Michael A. K. (1985) An Introduction to Functional Grammar. London: Edward Arnold. Huddlestone, Rodney and Geoffrey K. Pullum (2002) The Cambridge Grammar of the English Language. Cambridge: Cambridge University Press.

Jacobs, Geert (1999a) Preformulating the News. Amsterdam and Philadelphia: John Benjamins.

Jacobs, Geert (1999b) "Self-reference in press releases". Journal of Pragmatics 31, 219-242

Lassen, Inger (2004) "Ideological resources in biotechnology press releases: Patterns of Theme/ Rheme and Given/New". In: Young, Lynne and Claire Harrison (eds.) Systemic Functional Linguistics and Critical Discourse Analysis. London and New York: Continuum, 264-279.

Maat, H. Pander (2007) "How promotional language in press releases is dealt with by journalists: genre mixing or genre conflict?" The Journal of Business Communication 44 (1), 59-95.

McLaren, Yvonne and Calin Gurau (2005) "Characterising the Genre of the Corporate Press Release". LSP \& Professional Communication 5 (1), 10-29.

Mulderrig, Jane (2003) "Consuming education: a critical discourse analysis of social actors in New Labour's education policy”. Journal for Critical Education Policy Studies 1 (1). The Institute for Education Policy Studies (IEPS), 96-123.

Põiklik, Pille (2012) "Recontextualisation of the Second Amendment and Supreme Court Decisions in The New York Times'. Brno Studies in English 38 (1), 24-37.

Quirk, Randolph, Sidney Greenbaum, Sidney, Geoffrey Leech and Jan Svartvik (1985) A Comprehensive Grammar of the English Language. London: Longman.

Ungerer, Friedrich (2004) "Ads as news stories, news stories as ads: The interaction of advertisements and editorial texts in newspapers". Text 24(3), 307-328.

van Dijk, Teun A. (1985) "Structures of news in the press". In: van Dijk, T. A. (ed.) Discourse and Communication: New Approaches to the Analysis of Mass Media Discourse and Communication. Berlin: de Gruyter, 69-93. 
van Leeuwen, Theo (1996) “The representation of social actors'. In: Caldas-Coulthard, Carmen Rosa and Malcolm Coulthard (eds.) Texts and Practices: Readings in Critical Discourse Analysis. London: Routledge, 32-70.

van Leeuwen, Theo (2008) Discourse and Practice: New Tools for Critical Discourse Analysis. Oxford: Oxford University Press.

Walters, William and Jens Henrik Haahr (2005) Governing Europe. Discourse, Governmentality and European Integration. London: Routledge.

Danica Maleková is a lecturer at the Department of English Language and Literature, Catholic University, Ružomberok, Slovakia. From 2005 to 2011 she worked as a translator and later administrator in the European Commission. She gained her PhD (2010) from Masaryk University in Brno, the Czech Republic, with the dissertation titled The Genre of Institutional Press Release - A Critical Discourse Analysis. Her main teaching and research areas include stylistics, critical discourse analysis and translation, focusing on environmental discourse.

Address: PhDr. Danica Maleková, PhD., Department of English Language and Literature, Faculty of Arts, Catholic University, Hrabovská cesta 1, 03401 Ružomberok, Slovakia. [email: danica. malekova@ku.sk] 